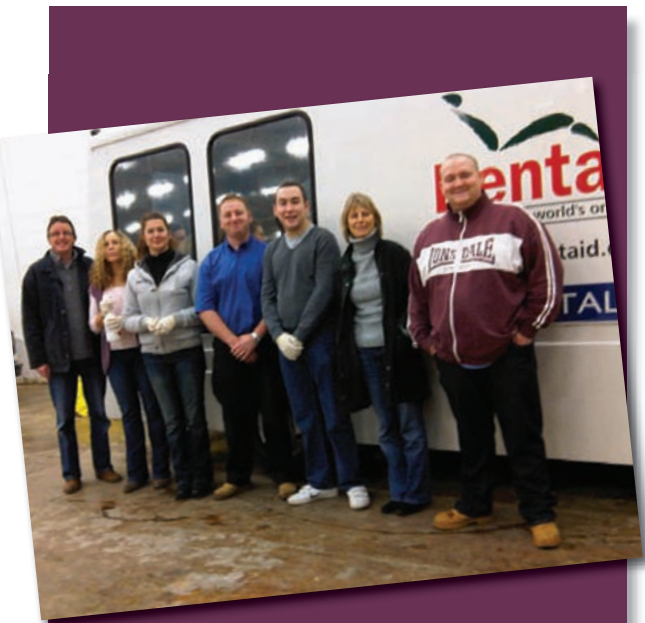

\section{VOLUNTEERS JOIN CRISIS CHRISTMAS}

Last Christmas the charity Crisis opened its doors to the homeless for the 39th consecutive year in a specific campaign that has become known as Crisis Christmas.

Nine centres in London welcomed almost 2,000 guests, who as well as taking advantage of warm meals, companionship and accommodation, were also able to access other essential services and learning resources.

In 2009, as in the previous four years, a team from Henry Schein joined over 8,000 other volunteers and for the first time all three divisions of the Henry Schein Group were involved: dental, medical and veterinary, the latter supplying collars and leads for many of the guests' dogs.

One of the services offered by Crisis is access to dental facilities and Henry Schein arranges and co-ordinates the set-up and close-down of two dental units located at one of the Crisis centres. Each unit is staffed by fully qualified volunteer dentists and support staff. Treatments range from basic oral care and hygiene to root canal therapy and extractions. In 2009 a total of 270 treatments were performed by the dental teams on site.

Crisis run campaigns throughout the year aimed at bringing the plight of homeless people to the attention of government and the public. To volunteer or donate visit www.crisis.org.uk.

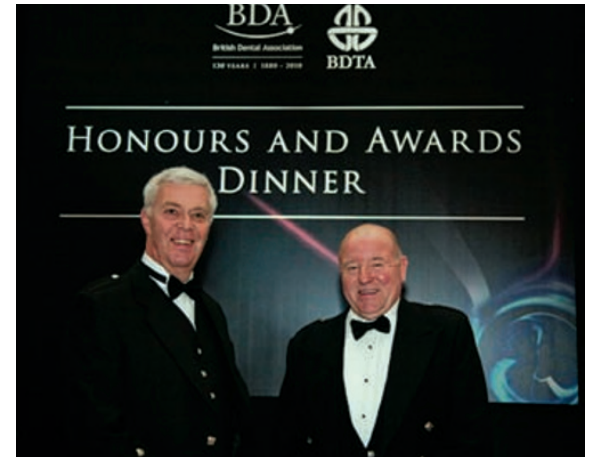

\section{DENTAL TECHNICIAN HONOURED}

Brian Gordon was awarded an Honorary

Fellowship of the Dental Technologists

Association (DTA) at the 2009 BDA Honours and Awards Dinner. Brian received the award for his positive impact on dental technology and associated patient care over many years.

Presenting the Honorary Fellowship on behalf of the DTA Council, Tony Griffin said 'This honour is awarded to an individual who has not only worked tirelessly in developing the future of dental care and the profession of dental technology but who has gone significantly beyond what would have been expected of a member of our profession.'

During the evening, an award for contribution to clinical dental technology was presented to Kevin Manners and an award in appreciation of her dental nursing activities was given to Janet Goodwin.

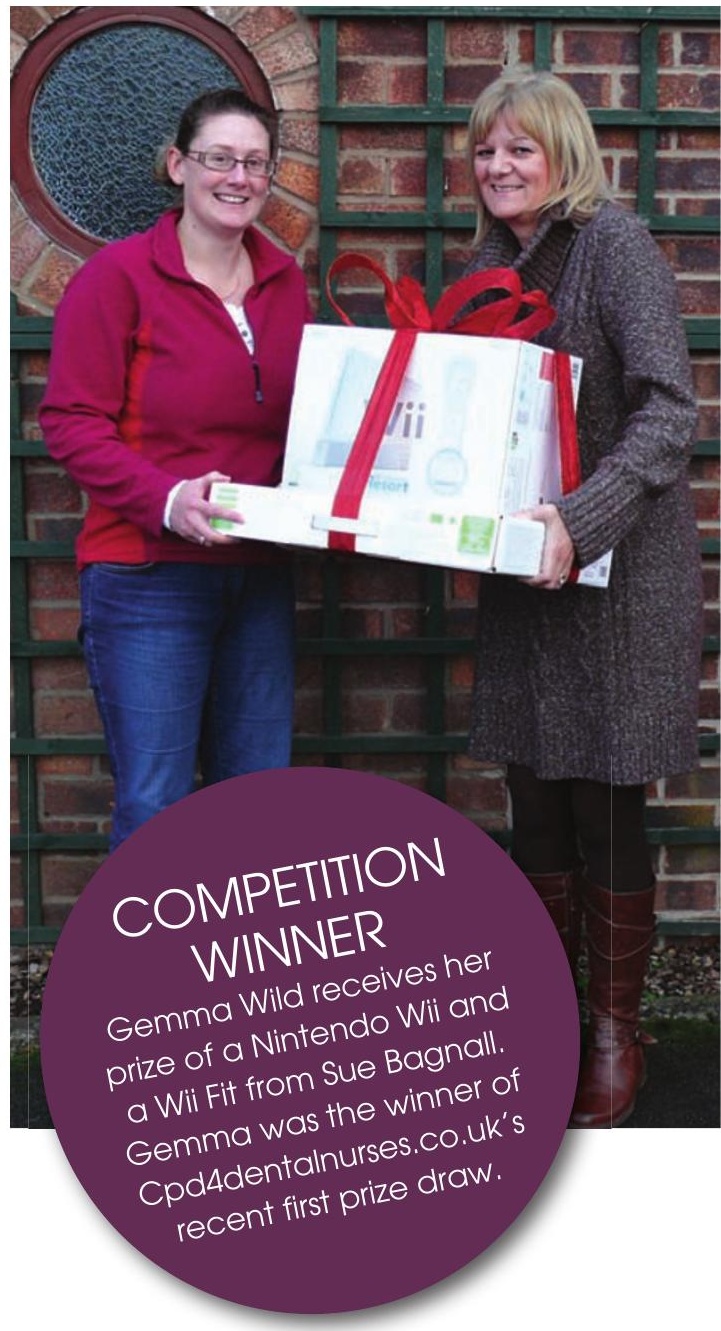

